\title{
EXPRESIÓN DE RECEPTORES DE LEPTINA EN GLÁNDULA MAMARIA DE BOVINOS LACTANTES Y NO LACTANTES
}

\section{LEPTIN RECEPTOR EXPRESSION IN MAMMARY GLAND OF LACTATING AND NO LACTATING COWS}

\author{
Diana Echeverry ${ }^{1}$, Zulma Tatiana Ruiz-Cortés ${ }^{2}$ \\ ${ }^{1}$ MV, e-mail: dianaecheverrymv@hotmail.es; ${ }^{2}$ MV, MSc., PhD., docente e investigadora, grupo BIOGÉNESIS. Universidad \\ de Antioquia. Carrera 75\#65-87, Ciudadela Robledo, bloque 46-114, Medellín, Colombia, e-mail: zulma.ruiz@udea.edu.co
}

Rev. U.D.C.A Act. \& Div. Cient. 18(1): 171-179, Enero-Junio, 2015

\section{RESUMEN}

Los niveles de la hormona leptina y la expresión de sus receptores en glándula mamaria bovina parecen ejercer una función en el desarrollo del tejido secretor durante la pubertad. Se ha relacionado la presencia de estos receptores con mamogénesis y con regulación de síntesis de ácidos grasos. Existen estudios de la hormona y su receptor durante la pubertad y en el período posparto. También, se conoce acerca de presencia de los transcriptos de la hormona y de su receptor en glándula mamaria, en vacas secas preñadas, así como en el período de lactancia. Así, el objetivo de este estudio fue estudiar la expresión (transcripto y proteína) de los receptores de leptina, isoformas Ob-ra y Ob-rb, en glándula mamaria de vacas Holstein, durante la lactancia vs. el periodo seco. Se confirmó, por medio de las técnicas de RT-PCR y de Western blot, que los receptores de leptina se expresan en glándula mamaria. Los resultados de la RT-PCR mostraron expresión de ambas isoformas (ARNm) en los dos periodos, sin diferencia estadística; sin embargo, la proteína de la isoforma Ob-ra fue identificada solo en el periodo seco, mientras que la de la isoforma $\mathrm{Ob}-\mathrm{rb}$ fue encontrada durante la lactancia y en el periodo seco, sin diferencia estadística, al comparar los niveles de expresión. Los datos muestran un perfil de expresión diferente en las vacas Holstein del estudio, en comparación con lo reportado en la literatura para otros rumiantes no especializados, en la producción de leche.

Palabras clave: Lactancia, glándula mamaria, gen de leptina.

\section{SUMMARY}

Leptin hormone levels and expression of its receptors in mammary gland may be important regulators of secretory tissue during puberty. Receptor expression has been related with mammogenesis and with fatty acids synthesis. There are studies about the hormone and its receptors during puberty and postpartum. Also, the transcripts of leptin and receptors have been described in dry pregnant cows' mammary gland as well as during lactating period. The objective of this study was to determine the expression level of leptin receptors (transcripts and proteins), isoforms Ob-ra and Ob-rb, in Holstein cows during lactation vs. dry periods. The presence of leptin receptors in mammary gland was confirmed by RT-PCR and Western blot technics. However, the Ob-ra was identified only in no lactating cows while isoform Ob-rb was found in both lactating and dry periods without statistical difference when levels of expression were compared. RTPCR results indicated mRNA expression of both isoforms receptors with no significant difference when two periods were compared. Data suggest a differential profile of expression of leptin receptors in Holstein cows of this study compared to reports in no specialized milk producer ruminants.

Key words: Lactation, mammary gland, leptin gene.

\section{INTRODUCCIÓN}

En caprinos, se han identificado células de glándula mamaria que producen leptina, como los adipocitos y las células mioepiteliales; otras presentan receptores, como los lactocitos o células epiteliales (Li et al. 2010). Es de interés el estudio de los niveles de expresión del receptor en glándula mamaria en la vaca, en sus diferentes niveles celulares y en otros tejidos, claves en el metabolismo mamario, para entender las diferentes interacciones y contribuir a la comprensión de sus efectos en la fisiología productiva y reproductiva (Chelikani et al. 2003; Silva et al. 2002; Thorn et al. 2006).

En bovinos, transcriptos de ARNm de leptina, fueron detectados en el parénquima mamario y en tejido adiposo (Chelikani et al. 2003). Igualmente, se ha reportado expresión de transcriptos de leptina y de sus receptores, principalmente, en células epiteliales de vaca en lactancia, mientras que en tejido mamario de vacas secas, la señal se encontró, igual- 
mente, en tejido estromal (Sayed-Ahmed et al. 2004). En otros modelos de estudio in vitro con la línea celular MAC-T y en células aisladas de tejido mamario, el ARNm de la isoforma larga del receptor (Ob-Rb) fue encontrado (Silva et al. 2002).

Algunos estudios en ovinos y en caprinos plantean que la leptina tiene un papel en la regulación directa del crecimiento y desarrollo del parénquima de la glándula mamaria y que ejerce un rol paracrino y autocrino en la proliferación, la diferenciación y la apoptosis de las células epiteliales mamarias (CEM), de los adipocitos y de las células mioepiteliales (Laud et al. 1999; Li et al. 2010). Durante los diferentes estadios reproductivos hubo diferencias significativas en los niveles de expresión de receptores de leptina en la glándula mamaria de cabras, lo que sugiere que el efecto local de la hormona también es distinto según la etapa (Li et al. 2010).

Es conveniente citar los resultados hallados por Bonnet et al. (2002), donde la determinación cuantitativa de los niveles de ARNm por q-PCR en tiempo real, mostró que la expresión de leptina en pequeños rumiantes fue alta durante la primera mitad de la preñez y menos marcada, durante el periparto, mientras que los niveles de ARNm de los receptores de leptina fueron mayores entre los 70 y 106 días de preñez y menores, durante la finalización de la gestación y el inicio de la lactancia. Además, se han observado diferencias en la proporción de isoformas corta y larga del Ob-R en el tejido mamario de ovinos y bovinos, ya que las células epiteliales mamarias, de esta última especie, expresan, en mayor medi$\mathrm{da}$, la isoforma larga, mientras que en los ovinos predomina la expresión de la isoforma corta (Bonnet et al. 2002). En cabras, se conoce que la leptina induce la expresión del receptor OB-Rb en glándula mamaria y controla el desarrollo y la función fisiológica en la glándula mamaria, por unión al receptor (Vernon et al. 2002).

Siendo el período de lactancia crítico para el metabolismo del animal, se ha estudiado el efecto de la leptina frente a dietas altamente energéticas y, se concluyó, que la leptina media efectos inhibitorios de las dietas ricas en energía sobre el desarrollo de la glándula mamaria, vía regulación de los niveles de factor de crecimiento tipo insulina-I (IGF-I) (Silva et al. 2002).

En cultivos in vitro tridimensionales de tejido mamario, la leptina tuvo efecto inhibitorio en la proliferación de las CEM bovinas, aun cuando éstas fueron suplementadas con factores de crecimiento, como factor de crecimiento hepático (HGF), compuesto que interviene la proliferación de las CEM durante la morfogénesis de las estructuras ductales (Yamaji et al. 2007). Esto coincide con un estudio de Silva et al. (2008), donde se demostró in vivo que la aplicación de leptina por el canal del pezón regula la proliferación del epitelio de los conductos y los alvéolos mamarios, disminuyendo en un $48 \%$ la cantidad de CEM en la fase $S$ del ciclo celular, mediante la expresión de caspasa 3 (Silva et al. 2008). Lo anterior, sugiere que la disminución de los niveles de leptina, en el segundo tercio de la gestación, permite que se dé la formación de conductos glandulares. Se ha encontrado que la interacción de la leptina con las hormonas lactogénicas, como la prolactina, la insulina, la somatotropina y el cortisol, controla la proliferación de CEM (Yonekura et al. 2006). Se ha observado que la leptina regula el efecto de la prolactina sobre la síntesis de ácidos grasos, alfa caseína y beta lactoalbumina, aumentando la síntesis de estos componentes de la leche en cultivos in vitro de explantes de tejido mamario de vacas; por otro lado, la prolactina aumentó 25 veces la expresión del receptor de leptina, lo que sugiere que la prolactina aumenta la sensibilidad a la leptina (Feuermann et al. 2004; Silva et al. 2008). Así, se ha demostrado que los efectos fisiológicos, las interacciones endocrinas y las vías de señalización desencadenadas por la leptina y sus receptores en las CEM, podrían contribuir a encontrar estrategias que mejoren la calidad nutricional de la leche, como fue revisado hace algunos años (Echeverry et al. 2012).

Se hace necesario continuar con la investigación básica, con la finalidad de describir la importancia del receptor de leptina en glándula mamaria bovina, durante la lactancia y el periodo en el que la glándula mamaria no se encuentra activa, con el objetivo de comprender la participación de la leptina y su vía de señalización celular, en este órgano tan importante para la producción láctea.

La hipótesis de este trabajo es que la expresión de receptores de leptina (Ob-Ra y Ob-Rb), en glándula mamaria de bovinos Holstein, varía entre los estadios de lactancia y periodo seco.

\section{MATERIALES Y MÉTODOS}

Animales: Se utilizaron 28 vacas de la raza Holstein, 13 en periodo de lactancia y 15 en periodo seco, no gestantes. Se tuvieron en cuenta las siguientes condiciones: animales bovinos, hembras, raza Holstein, condición corporal entre 2,75 y 3,5 según escala de 1 a 5 y evaluado por una única persona (Álvarez, 1997), con registro de procedencia disponible en la Central de abasto. Entre los criterios de exclusión de la muestra, se tuvieron en cuenta: patologías, como mastitis, metritis, retención de placenta, enfermedades infectocontagiosas y razas diferentes a Holstein; todos estos criterios, según registro disponible en la central ganadera antes del sacrificio.

Los animales procedían de explotaciones lecheras del municipio de Santa Rosa de Osos, Antioquia, ubicado a 2581 msnm, en bosque húmedo montano bajo, con precipitación media anual de $2238 \mathrm{~mm}$, humedad relativa del $79 \%$ y temperatura promedio de $13^{\circ} \mathrm{C}$. Fueron alimentados con 
pasto kikuyo (Pennisetum clandestinum), días antes del sacrificio.

Toma de muestras: Las muestras se obtuvieron periódicamente, de acuerdo al número de hembras Holstein disponibles en la planta de beneficio; esto dependió de la renovación de lotes, del descarte por vida útil, del alimento y el espacio a disposición del estudio y de las patologías de diversos tipos. Para la realización del proyecto, se contó con la aprobación del Comité de Ética para la Experimentación con Animales de la Universidad de Antioquia (Acta 69, 3 de mayo del 2011).

Se tomaron muestras de tejido mamario glandular profundo por cada cuarto, se hizo un pool para constituir una muestra y esto se repitió dos veces, para continuar con los análisis. El tamaño de cada muestra fue de, aproximadamente, $0,5 \mathrm{~mm}$ de espesor y se tomó justo después del sacrificio en la planta de beneficio, de acuerdo a la metodología de Sayed et al (2003). Una muestra, se depositó en un tubo de ensayo de $2 \mathrm{~mL}$ (Eppendorf, USA), debidamente rotulado, esterilizado y tratado con inhibidor de RNAsas, con $100 \mu \mathrm{L}$ de ice cold RNALATER (Qiagen ${ }^{\circledR}$, Alemania), con el fin de preservar el ARN de la muestra, para su posterior extracción, según metodología propuesta anteriormente (Sayed-Ahmed et al. 2003). La segunda muestra, se depositó en otro tubo de ensayo de $2 \mathrm{~mL}$ (Eppendorf, USA), con $200 \mu \mathrm{L}$ de solución salina tamponada con fosfato-PBS, con $\mathrm{pH} 7.6$, para posterior extracción de proteínas. Se tomaron otras muestras de bazo e hígado para ser procesadas y utilizadas en el ensayo, como controles positivos de la expresión de receptores de leptina. Las muestras, se mantuvieron refrigeradas con geles refrigerantes durante el transporte, a una temperatura aproximada de $0^{\circ} \mathrm{C}$ y se almacenaron en congelador a $-80^{\circ} \mathrm{C}$, hasta que fueron procesadas para los diferentes ensayos de proteína y de RNAm.

Técnica Western Blot: Se utilizó para identificar el receptor de leptina en la glándula mamaria. Este proceso consistió en la extracción de las proteínas del tejido glandular mamario, electroforesis, transferencia e inmunoblotting.

Extracción de proteínas: Se realizó por maceración de la muestra con Buffer RIPA (del inglés RadiolmmunoPrecipitation Assay) modificado (50mM Tris- $\mathrm{HCl}(\mathrm{pH} 8,0), 1 \mathrm{mM}$ EDTA, $500 \mathrm{mM} \mathrm{KCl}, 2 \mathrm{mM}$ ditiotreitol (DTT), 0,05\% cóctel inhibidor de la proteasas $0,05 \%$ cóctel inhibidor de proteasas amresco ${ }^{\circledR}$ M222 que contiene AEBSF: Aprotinina, Bestatina, E-64, Leupeptina y EDTA (Domínguez et al. 2008). Luego de la extracción, se sometieron a sonicación las muestras, durante cinco minutos, en un equipo Misonix ${ }^{\circledR}$, Canadá. Se midió la concentración de proteínas en ug/mL, con el Kit Pierce BCA de Thermo®, USA.
Electroforesis en SDS-PAGE: La preparación del extracto de proteínas, se realizó con Buffer Laemmli (1,25M Tris-HCl $\mathrm{pH} 6,8$ con beta-mercaptoetanol al $10 \%$, azul de bromofenol $(0,04 \%)$, glicerol $(20 \%)$, SDS $(4 \%)$ y se calentó a $55^{\circ} \mathrm{C}$, durante cinco minutos, según Li et al. (2010). Se utilizó un marcador de peso molecular (Fermentas $®$ ), para determinar el peso en KDa de las proteínas, 102 y 120 kDa para Ob-Ra y $\mathrm{Ob}-\mathrm{Rb}$, respectivamente. En cada pozo, se sirvieron $20 \mu \mathrm{g}$ de proteína. Se refectuó electroforesis en SDS-PAGE (6\%) (contenía agua destilada, acrilamida (30\%), 1,5M Tris-HCl, SDS (10\%), amonio persulfato (10\%), TEMED), debido al tamaño de la proteína; se utilizaron 100 voltios durante dos horas (Domínguez et al. 2008).

Transferencia e inmunoblotting: Se realizó transferencia a una membrana de nitrocelulosa a 200 miliamperios, durante dos horas, a $4^{\circ} \mathrm{C}$. Se realizó el bloqueo de la membrana, durante una hora, en solución de bloqueo (Tween PBS y leche al 5\%), a temperatura ambiente y en agitación constante. Luego, se realizaron tres lavados, cada uno de cinco minutos, con PBS Tween y, posteriormente, se procedió a incubar con el anticuerpo primario (Rabbit Anti-Mouse OBR IgG de Alpha Diagnostic $\left({ }^{\circledR}\right)$, a una dilución 1:500 en solución de bloqueo, toda la noche, a $4^{\circ} \mathrm{C}$ y en agitación constante. Pasado el tiempo de incubación, se realizaron tres lavados de cinco minutos cada uno, con solución PBS-Tween. Luego, se incubó la membrana con el segundo anticuerpo (Goat AntiRabbit IgG Horseradish Peroxidase conjugate BIORAD $\left.{ }^{2}\right)$, a una dilución de 1:1000, durante una hora, en agitación moderada, a temperatura ambiente. Se efectuaron tres lavados de cinco minutos cada uno, con solución PBS-Tween. El revelado de la membrana, se hizo con la solución de diaminobencidina de Amresco ${ }^{\circledR}$ (USA), para observar las bandas de interés, según otros autores (Domínguez et al. 2008; Li et al. 2010).

Técnica RT-PCR: Se tuvo en cuenta el protocolo utilizado por otros autores, con algunas modificaciones (Kawachi et al. 2007; Li et al. 2010). Extracción ARN: De las muestras congeladas en RNAlater, se tomaron 30mg de tejido, aproximadamente, para realizar extracción, con un kit comercial (RNeasy Fibrous Tissue de Qiagen $®)$. Transcripción Reversa y PCR: Para la transcripción reversa, se utilizó el kit RT-PCR One step ${ }^{\circledR}$, kit de un solo paso, que combina la síntesis de la primera cadena de cDNA y la reacción de PCR en el mismo tubo, simplificando la reacción y reduciendo las posibilidades de contaminación.

Para el estudio, se requirió de 1ug de ARN, en un volumen total de reacción de $25 \mu \mathrm{L}$, que contenía agua libre de RNasas, 5X RT-PCR buffer, dNTPs mix (10mM de cada uno), 0,6uM de cada primer, RT-PCR Enzyme mix. Para la amplificación de OB-Ra, el perfil térmico fue de treinta minutos, a $50^{\circ} \mathrm{C}$, para la transcripción reversa; quince minutos, a $95^{\circ} \mathrm{C}$, 
para la activación de la $\mathrm{PCR}$, seguido de 40 ciclos, de un minuto, a $94^{\circ} \mathrm{C}$, un minuto a $52^{\circ} \mathrm{C}$ y un minuto a $72^{\circ} \mathrm{C}$; finalmente, durante diez minutos, a $72^{\circ} \mathrm{C}$, para una extensión final. Para la amplificación de OB-Rb, el perfil térmico fue de treinta minutos, a $50^{\circ} \mathrm{C}$, para la transcripción reversa, quince minutos, a $95^{\circ} \mathrm{C}$, para la activación de la PCR, seguido de 40 ciclos, de un minuto, a $94^{\circ} \mathrm{C}$, un minuto a $47^{\circ} \mathrm{C}$ y un minuto a $72^{\circ} \mathrm{C}$; finalmente, durante diez minutos, a $72^{\circ} \mathrm{C}$, para una extensión final.

Para la amplificación del gliceraldehido 3- fosfato deshidrogenasa, GAPDH, como gen de referencia para normalizar la expresión del receptor, por medio del cálculo de la relación OBR/GAPDH; el perfil térmico fue de treinta minutos, a $50^{\circ} \mathrm{C}$, para la transcripción reversa; quince minutos, a $95^{\circ} \mathrm{C}$, para la activación de la PCR, seguido de 30 ciclos, de un minuto, a $94^{\circ} \mathrm{C}$, un minuto a $52^{\circ} \mathrm{C}$ y durante diez minutos, a $72^{\circ} \mathrm{C}$, para una extensión final (Sayed-Ahmed et al. 2003). Los cebadores utilizados para cada reacción, se reportan en la tabla 1. Los productos de la PCR fueron detectados por electroforesis en gel de agarosa al 1,5\%, que contenía Bromuro de Etidio $(0,7 \mu \mathrm{g} / \mathrm{mL})$. La localización de los productos esperados, se confirmó por el uso de un marcador de peso molecular de 50bp (Sayed-Ahmed et al. 2003).
Análisis estadístico: La variable dependiente fue la expresión de los receptores de leptina y la independiente el estado de la vaca seca o en lactancia. Se analizaron los datos de semicuantificación de proteína y ARNm de cada grupo, mediante estadística descriptiva, incluyendo: promedio, desviación estándar y distribución normal. Se realizó normalización de los datos de expresión de proteínas, a través de la división del valor de semicuantificación de la banda de rojo Ponceau, por el valor de la semicuantificación de la banda revelada por diaminobencidina. La normalización de los datos de expresión de la semicuantificación del ARNm obtenidos por Gel Quant Express ${ }^{\circledR}$, con unidad arbitraria, se realizó mediante la división de los datos de las isoformas, entre los datos de semicuantificación de la expresión del gen de referencia GAPDH. Se utilizó la prueba de normalidad Shapiro-Wilk. Se transformaron los datos en raíz cuadrada. Se aplicó la prueba de Levene, para evaluar homogeneidad de varianzas y la prueba T, para muestras independientes, con la finalidad de evaluar igualdad de medias, tanto de la expresión de ARNm como de proteína, para los receptores. Se realizó la prueba de Pearson, para evaluar si existía una correlación entre el nivel de expresión de la proteína y el de ARNm. Se trabajó con una significancia del 95\% $(p<0.05)$, con el paquete estadístico IBM-SPSS Statistics, versión 22.0.

Tabla 1. Secuencias de los cebadores usados para la RT-PCR de los genes de receptores de leptina (Ob-ra y Ob-rb) y para el gen constitutivo GAPDH.

\begin{tabular}{|l|l|l|c|l|}
\hline \multicolumn{1}{|c|}{ CEBADOR } & \multicolumn{1}{|c|}{ SENTIDO } & \multicolumn{1}{c|}{ ANTISENTIDO } & \multicolumn{1}{c|}{$\begin{array}{c}\text { TAMAÑO DEL } \\
\text { FRAGMENTO bp }\end{array}$} & \multicolumn{1}{c|}{ REFERENCIA } \\
\hline Ob-ra & $\begin{array}{l}\text { ACACCAGCATG } \\
\text { ATGCAGATCTA }\end{array}$ & $\begin{array}{l}\text { CAAAGAATGT } \\
\text { CCGTTCTCTTC }\end{array}$ & 185 & (Kawachi et al. 2007) \\
\hline Ob-rb & $\begin{array}{l}\text { AGGGTTCTATTT } \\
\text { GTATTAGTGACC }\end{array}$ & $\begin{array}{l}\text { GAAATTTCCCTCAA } \\
\text { GTTTCAAAAG }\end{array}$ & 353 & $\begin{array}{l}\text { (Sayed-Ahmed et al. } \\
\text { 2003) }\end{array}$ \\
\hline GAPDH & $\begin{array}{l}\text { TGCTGGTGCTG } \\
\text { AGTATGTGGT }\end{array}$ & $\begin{array}{l}\text { AGTCTTCTGGG } \\
\text { TGGCAGTGAT }\end{array}$ & 296 & Blast primer NCBI \\
\hline
\end{tabular}

\section{RESULTADOS Y DISCUSIÓN}

La expresión de proteína del receptor de leptina fue evaluada en las vacas que no se encontraban lactando y en las de periodo de lactancia. La isoforma Ob-rb, se encontró en ambos grupos analizados, como se observa en la tabla 2 y en la figura 1; la isoforma Ob-ra no se encontró en las vacas en periodo de lactancia, como se aprecia en la figura 1. La tabla 3 muestra que no hubo diferencia estadística en la expresión de la isoforma Ob-rb, entre los dos grupos analizados.
La expresión del ARNm del receptor de leptina de las isoformas Ob-ra y Ob-rb fue evaluada en un total de 25 muestras, 11 de vacas que no se encontraban lactando y 14 a vacas en periodo de lactancia. El ARNm de ambas isoformas, se encontró en los dos grupos analizados. No hubo diferencia estadística en la expresión de las isoformas, Ob-ra y Ob-rb, entre los dos grupos analizados, como descrito en la tabla 4 y en la figura 2. 
Tabla 2. Tabla de distribución de los datos de expresión de la proteína del receptor de leptina, isoforma Ob-rb en las vacas en periodo seco y lactancia.

\begin{tabular}{|c|c|c|c|}
\hline PERIODO & N & PROMEDIO & SD \\
\hline Seca & 15 & 1,07 & 0,466 \\
\hline Lactancia & 13 & 1,32 & 0,7 \\
\hline
\end{tabular}

Tabla 3. Expresión del receptor de leptina, Ob-ra y Ob-rb, en vacas en periodo seco y lactancia. Letras iguales indican que no hay diferencia estadística.

\begin{tabular}{|l|c|c|c|c|}
\hline \multirow{2}{*}{$\begin{array}{c}\text { Expresión } \\
\text { Proteína }\end{array}$} & \multicolumn{2}{|c|}{ SECA } & \multicolumn{2}{c|}{ LACTANCIA } \\
\cline { 2 - 5 } & $\mathbf{N}$ & Promedio +/- SD & $\mathbf{N}$ & Promedio +/- SD \\
\hline Ob-Ra & 15 & $0,06 \pm 0.9$ & 13 & 0 \\
\hline Ob-Rb & 15 & $1,01 \pm 0,4^{\mathrm{a}}$ & 13 & $1,32 \pm 0,7^{\mathrm{a}}$ \\
\hline
\end{tabular}

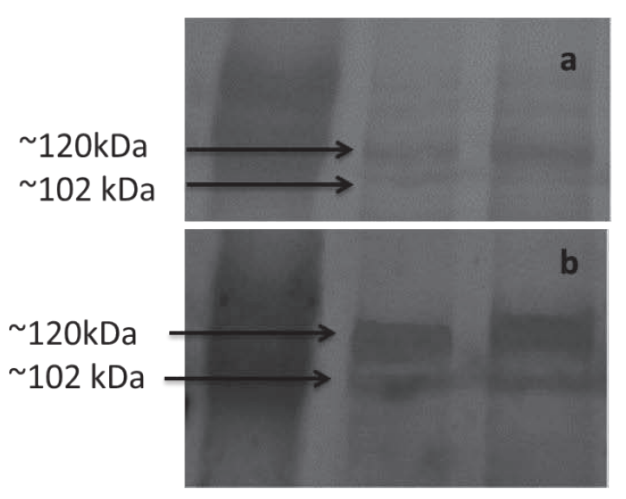

Periodo seco

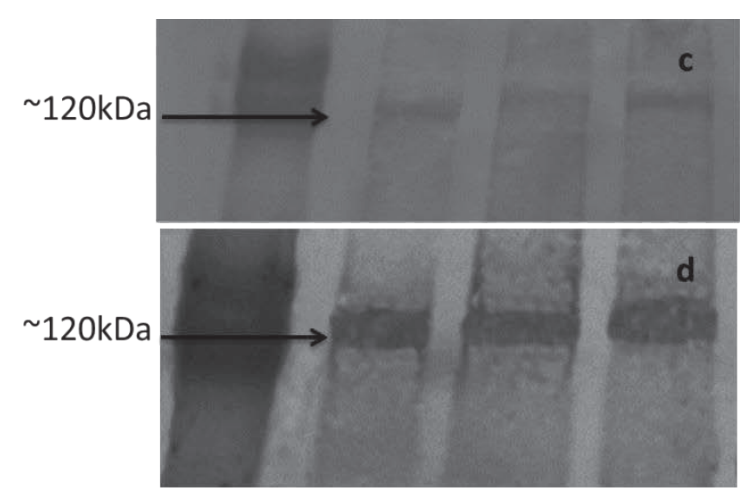

Lactancia

Figura 1. Western Blot. (a) Membrana teñida con rojo Ponceau, bandas de las isoformas a y b del receptor de leptina; (b) Membrana revelada con diaminobencidina, bandas de la isoforma a $(102 \mathrm{kDa})$ y de la isoforma b $(120 \mathrm{kDa})$ del receptor de leptina. Membranas a y b: vacas en periodo seco; (c) Membrana teñida con rojo Ponceau, banda de isoforma b del receptor de leptina;. (d) Membrana revelada con diaminobencidina: banda de isoforma b del receptor del leptina. Membranas c y d: vacas en periodo de lactancia.

Tabla 4. Expresión del ARNm de los receptores de leptina, Ob-ra y Ob-rb, en vacas en periodo seco y lactancia. Letras iguales indican que no hay diferencia estadística.

\begin{tabular}{|l|c|c|c|c|}
\hline \multirow{2}{*}{$\begin{array}{c}\text { Expresión } \\
\text { ARNm }\end{array}$} & \multicolumn{2}{|c|}{ SECA } & \multicolumn{2}{c|}{ LACTANCIA } \\
\cline { 2 - 5 } & $\mathbf{N}$ & Promedio +/- SD & $\mathbf{N}$ & Promedio +/- SD \\
\hline Ob-Ra & 11 & $1,1 \pm 0,5^{\mathrm{a}}$ & 14 & $0,9 \pm 0,5^{\mathrm{a}}$ \\
\hline Ob-Rb & 11 & $1,4 \pm 0,9^{\mathrm{a}}$ & 14 & $1,6 \pm 0,8^{\mathrm{a}}$ \\
\hline
\end{tabular}




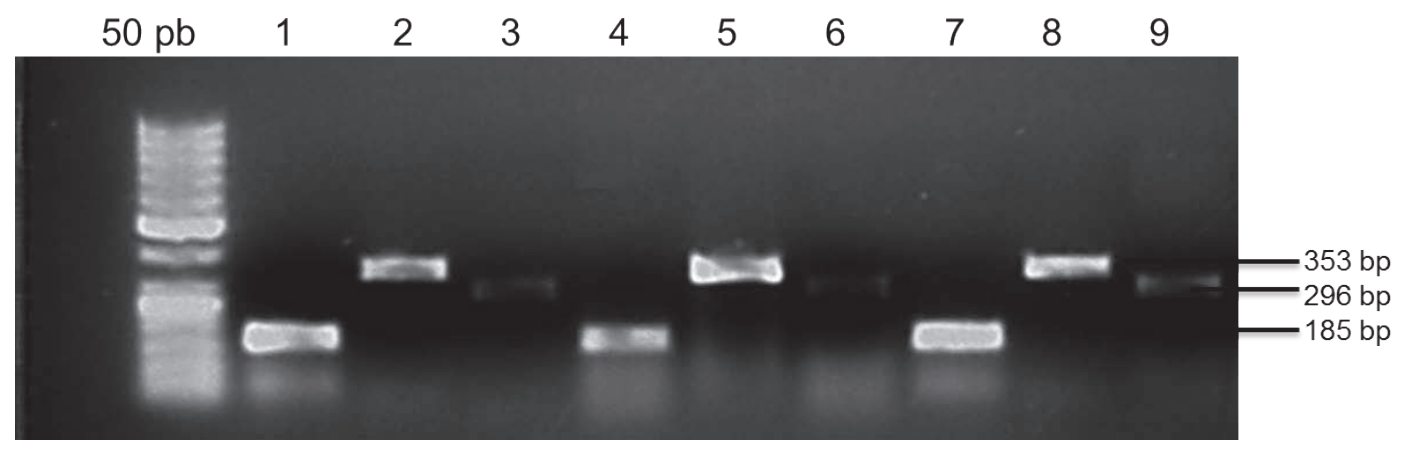

Figura 2. RT-PCR del receptor de leptina. Las líneas 1 a 6 corresponden, en su orden, a isoforma Ob-ra, Ob-rb y gen de referencia GAPDH, de dos vacas en periodo de lactancia. Las líneas 7, 8 y 9 corresponden, en su orden, a isoforma Ob-ra, Ob-rb y gen de referencia GAPDH, a una vaca no lactante.

Los datos de la prueba de Pearson no arrojaron correlación significativa entre el nivel de expresión de la proteína y el ARNm, por lo que se puede concluir que ambas son variables completamente independientes, en este caso.

En el presente estudio, se confirmó que el receptor de leptina, Ob-rb y Ob-ra, se expresa en glándula mamaria, tal como lo han encontrado otros autores (Chelikani et al. 2003; Sayed-Ahmed et al. 2004), a través de la técnica RT-PCR, identificando el ARNm de ambas isoformas; sin embargo, por medio de la técnica Western Blot, se detectó la proteína del receptor isoforma Ob-ra solamente en las vacas no lactantes, mientras que la isoforma Ob-rb, se halló, tanto en las vacas lactantes como no lactantes. En este estudio, no se efectuó medición de la hormona leptina entre los grupos de estudio; sin embargo, partiendo de las diferencias encontradas, entre la expresión de esta hormona, en glándulas mamarias de hembras bovinas Holstein lactantes y no lactantes (Onda et al. 2013), donde en el último grupo la expresión del ARNm de leptina es muy bajo o casi nulo, se deseaba conocer la expresión del ARNm y la proteína de sus principales receptores, Ob-ra y Ob-rb. Aunque los resultados obtenidos en el presente estudio son más de tipo semicuantitativo que cuantitativo, se buscó establecer las posibles diferencias entre la expresión del ARNm y de la proteína. No hubo diferencias estadísticas en el análisis de los datos entre la presencia del receptor Ob-rb, en los periodos de interés; asimismo, los resultados de la RT-PCR demuestran que en los dos periodos analizados hay expresión del ARNm de las dos isoformas, sin diferencia estadística. Este estudio describe la expresión del ARNm y de la proteína de las isoformas Ob-ra y Ob-rb en bovinos, complementando estudios anteriores en rumiantes (Sayed-Ahmed et al. 2004; Silva et al. 2002).
Al comparar los resultados de este estudio con hallazgos en especies cercanas, se registran diferencias en la expresión de este receptor; por ejemplo, en ovinos, se ha reportado, por medio de hibridación in situ en células epiteliales mamarias, cambios en la expresión (ARNm) del receptor de leptina, durante la preñez y la lactancia, sugiriendo que, durante la preñez, el efecto de la leptina está dado sobre la diferenciación y la proliferación de las células epiteliales; sin embargo, no se determinó la presencia de la proteína (Laud et al. 1999). Es probable que entre ovinos y bovinos se encuentren las diferencias mencionadas, al comparar resultados, debido al tipo de análisis realizado. En ovinos, se determinó expresión genética en células epiteliales mamarias, mientras que en el presente estudio, se determinó en extracto total de glándula mamaria, en el cual, estaban, posiblemente, presentes adipocitos y células mioepiteliales. No se tienen más reportes para realizar comparación entre estas dos especies y determinar si las diferencias dadas son estadísticamente significativas; no obstante, los resultados que sugieren que la presencia de la proteína de las dos isoformas en glándula mamaria de bovino y su diferencia entre animales lactantes y no lactantes se puede relacionar con efectos dirigidos, principalmente, hacia la célula epitelial mamaria, que es la que sufre mayores cambios, durante las etapas de lactancia y periodo seco y es la principal célula que regula la producción láctea.

Estudios en rumiantes (Bartha et al. 2005; Li et al. 2010; Sayed-Ahmed et al. 2004) reportan que los receptores de leptina en glándula mamaria varían, considerablemente, dependiendo de la etapa reproductiva. Es así como en el tejido glandular mamario de búfalas la principal isoforma es la Obra en la expresión de ARNm, a pesar de que existe también la isoforma Ob-rb (Sayed-Ahmed et al. 2003). En cabras, se ha reportado que la principal isoforma es la Ob-rb, en su 
expresión de ARNm y de proteína, sin reporte alguno de secuenciación de la Ob-ra, mientras que en glándula mamaria de camellos fue secuenciada la isoforma Ob-ra y Ob-rb, pero no se ha establecido si existen diferencias entre el nivel de expresión de estas dos y si finalmente todo el ARNm encontrado es traducido a proteína (Bartha et al. 2005).

La expresión del receptor de leptina en glándula mamaria de hembras caprinas, durante diferentes etapas reproductivas, muestran diferencias en los periodos relacionadas con mayor mamogénesis, como es el periodo seco, en el cual, existe un aumento en la expresión de la leptina y su receptor. Durante el periparto, los niveles del receptor de leptina disminuyen, así como los de su hormona (Domínguez et al. 2008; Li et al. 2010; Rasmussen et al. 2008).

La expresión de leptina en cultivo de tejido, a partir de la glándula mamaria de vacas lactantes, aumentó 2,2 veces por efecto de la prolactina. Igualmente, en presencia de prolactina, la leptina estimuló la síntesis de ácidos grasos, así como la expresión de alfa-caseína y beta-lactoblobulina en explantes de glándula mamaria de vacas lactantes. Ningún efecto de la prolactina se detectó en la expresión de leptina y sus receptores en tejido de glándula mamaria de terneras en cultivo. Los hallazgos indicaban que la leptina juega un importante papel en la lactogénesis y que la expresión de leptina requiere la presencia de prolactina (Feuermann et al. 2004).

Altas concentraciones de leptina en la glándula mamaria reducen la proliferación de las células epiteliales mamarias. La baja en la proliferación, se acompaña de un aumento en la expresión de SOCS-3, lo que sugiere un posible mecanismo de inhibición por la leptina de la actividad de la IGF-I. Así, autores concluían que el efecto regulador fisiológico de la mamogénesis por parte de la leptina necesitaba aún ser determinado (Silva et al. 2008).

En 2010, se reportó que la leptina, específicamente, induce la expresión de su isoforma larga del receptor e influencia, en efecto, el desarrollo y la función mamarios, por medio de diferentes vías, mediadas por la kinasa Janus (JAK) (Li et al. 2010). De esta manera, aunque continuaba sin estar totalmente esclarecido el papel de la leptina en la glándula mamaria, era claro que influye directamente en los cambios en la eficiencia de la lactancia, actuando localmente en la glándula (Wall \& McFadden, 2012).

Más recientemente, se publicó que la leptina ejerce también una actividad autocrina y/o paracrina que afectaría el desarrollo ductal, la formación de los alvéolos, la expresión de los genes de proteínas de leche y el inicio de la involución (Baratta, 2012).
En el presente estudio, a pesar de no encontrar diferencia entre la isoforma Ob-rb, entre los dos periodos analizados, la presencia de la isoforma Ob-ra sugiere que la leptina podría estar implicada en la proliferación celular. Cuando hay una remodelación del tejido mamario es probable que esta vía sea una alternativa para hacer efectivo dicho proceso fisiológico, sin que aumente la expresión de la isoforma Ob-rb.

Al realizar la prueba de Pearson, entre la expresión de la proteína y el ARNm, no se encontró correlación significativa, como ocurrió en el estudio realizado por Li et al. (2010). Esta correlación es necesario repetirla en otro estudio, en el cual, los datos no sean de tipo semicuantitativo, para poder afirmar que no existe correlación. Esto también sugiere que la expresión del gen Ob-ra, durante la etapa de lactancia, no necesariamente significa que sea traducido en proteínas funcionales o se traduce en menores cantidades, que no se pudieron detectar en este ensayo. Chelikani et al. (2003) mostraron la muy amplia distribución de la expresión de los transcriptos del receptor de leptina (isoformas larga y corta), en 27 tipos de tejido del bovino (no se incluyeron tejido mamario); este hallazgo sugería el potencial efecto múltiple fisiológico de la hormona en ganado; sin embargo, y como los autores concluyen, se debía cuantificar la abundancia de dicho transcripto y realizar localización inmunohistoquímica, para poder concluir acerca de la presencia real de los receptores y de su significado funcional en los diferentes tejidos.

En porcinos, la raza ha sido demostrada como factor determinante en la expresión del RNAm, de la leptina y de sus receptores, según el tipo de producción a la que la raza se asigna (carne o grasa) (Georgescu et al. 2014). La identificación de la proteína de los receptores de leptina, Ob-ra y Ob-rb, en glándula mamaria en vacas Holstein en lactancia y periodo seco, sugieren que en esta especie y raza, en particular, la leptina podría tener un efecto en la remodelación mamaria, pero se necesita mayor investigación, para poder asegurar un efecto, según la raza y del tipo de producción.

De manera preliminar, se podría sugerir que la Ob-ra juega un papel crucial en la vía de señalización celular tan importante, como la principal isoforma y que, hasta el momento, se ha ignorado. Aunque no se comprueba la hipótesis de trabajo, que propone diferencias de expresión entre los dos periodos analizados, los datos obtenidos permiten sugerir la existencia de un perfil de expresión diferente en vacas lecheras, en comparación con el de otras especies rumiantes, las cuales, no son tan especializadas en producción láctea, como las vacas Holstein.

Otros estudios complementarios serían necesarios para determinar la vía de señalización de las isoformas Ob-r en glándula mamaria bovina, en el periodo seco y de lactancia; estudiar su interacción, no sólo con otras moléculas sino que 
igualmente con estados del animal, en cuanto a fotoperíodo, cantidad de tejido adiposo, tipo de alimentación y un listado casi interminable de características de microambiente endocrino y de condiciones externas en las se encuentra el animal, con el fin de aclarar cuál es el mecanismo específico por el cual podría ejercer las multi-funciones que se le asignan (Chelikani et al. 2003; Chilliard et al. 2001).

Se plantean otras hipótesis de trabajo, a partir de estos resultados, como que la isoforma Ob-ra desencadena, a través de su cascada de señalización, la expresión de genes, que intervienen en la remodelación mamaria.

Agradecimientos: A Frigocolanta en Santa Rosa de Osos, Antioquia-Colombia, por su apoyo en la toma de muestras. Financiación: CODI-Universidad de Antioquia, mediana cuantía - 2012 al grupo Biogénesis Estrategia Sostenibilidad 2013-14, Universidad de Antioquia al grupo Biogénesis. Conflicto de intereses: El manuscrito fue preparado y revisado con la participación de todos los autores, quienes declaramos que no existe conflicto de intereses, que ponga en riesgo la validez de los resultados presentados.

\section{BIBLIOGRAFÍA}

1. ÁlVAREZ, J.L. 1997. Condición corporal en la hembra bovina. Rev. Salud Animal. 19:37-45.

2. BARATTA, M. 2012. Role of Leptin in the Mammary Gland Development, Lactation and in Neonatal Physiology, p.89-106. En libro Leptin: Hormonal Functions, Dysfunctions and Clinical Uses. Nova Science Publishers.https:/www.novapublishers.com/ catalog/product_info.php?products_id=26303 (con acceso 13/03/2015).

3. BARTHA, T.; SAYED-AHMED, A.; RUDAS, P. 2005. Expression of leptin and its receptors in various tissues of ruminants. Domest Anim Endocrinol. 29:193202.

4. BONNET, M.; DELAVAUD, C.; LAUD, K.; GOURDOU, I.; LEROUX, C.; DJIANE, J.; CHILLIARD, Y. 2002. Mammary leptin synthesis, milk leptin and their putative physiological roles. Reprod. Nutr. Dev. 42:399413.

5. CHELIKANI, P.K.; GLIMM, D.R.; KENNELLY, J.J. 2003. Short communication: Tissue distribution of leptin and leptin receptor mRNA in the bovine. J. Dairy Sci. 86:2369-2372.

6. CHILLIARD, Y.; BONNET, M.; DELAVAUD, C.; FAULCONNIER, Y.; LEROUX, C.; DJIANE, J.; BOCQUIER,
F. 2001. Leptin in ruminants. Gene expression in adipose tissue and mammary gland, and regulation of plasma concentration. Domest Anim. Endocrinol. 21:271-295.

7. DOMÍNGUEZ, C.; RUIZ, A.Z.; PÉREZ, R.; MARTÍNEZ, N.; DRESCHER, K., PINTO, L.; ARANEDA, R. 2008. Efecto de la condición corporal al parto y del nivel de alimentación sobre la involución uterina, actividad ovárica, preñez y la expresión hipotalámica y ovárica de los receptores de leptina en vacas doble propósito. Rev. Fac. Cienc. Vet. 49:23-26.

8. ECHEVERRY, D.M.; PENAGOS, F.; RUIZ-CORTÉS, Z.T. 2012. Role of leptin and its receptor on bovine mammary gland. Rev. Col. Cienc. Pec. 25:500-510.

9. FEUERMANN, Y.; MABJEESH, S.J.; SHAMAY, A. 2004. Leptin affects prolactin action on milk protein and fat synthesis in the bovine mammary gland. J. Dairy Sci. 87:2941-2946.

10. GEORGESCU, S.E.; MANEA, M.A.; DINESCU, S.; COSTACHE, M. 2014. Comparative study of leptin and leptin receptor gene expression in different swine breeds. Genet. Mol. Res. 13:7140-7148.

11. KAWACHI, H.; YANG, S.H.; HAMANO, A.; MATSUI, T.; SMITH, S.; YANO, H. 2007. Molecular cloning and expression of bovine (Bos taurus) leptin receptor isoform mRNAs. Comparat. Biochem. Physiol. Part B: Biochem. Mol. Biol. 148:167-173.

12. LAUD, K.; GOURDOU, I.; BELAIR, L.; KEISLER, D.H.: DJIANE, J. 1999. Detection and regulation of leptin receptor mRNA in ovine mammary epithelial cells during pregnancy and lactation. FEBS Lett. 463:194-198.

13. LI, M.; LI, Q.; GAO, X. 2010. Expression and function of leptin and its receptor in dairy goat mammary gland. J. Dairy Res. 77:213-219.

14. ONDA, K.; SATO, R.; OBA, N.; HASHIMOTO, E.; OCHIAI, H.; ARAI, S.; KAWAI, K.; KANEKO, K.; ITOH, S.; WADA, Y. 2013. Leptin mRNA expression in the mammary gland of Holstein dairy cows. J. Animal Vet. Adv. 12:118-122.

15. RASMUSSEN, A.N.; NIELSEN, M.O.; TAUSON, A.H.; OFFENBERG, H.; THOMSEN, P.D.; BLACHE, D. 2008. Mammary gland leptin in relation to lactogenesis in the periparturient dairy goat. Small Rum. Res. 75:71-79. 
16. SAYED-AHMED, A.; ELMORSY, S.E.; RUDAS, P.; BARTHA, T. 2003. Partial cloning and localization of leptin and leptin receptor in the mammary gland of the Egyptian water buffalo. Domest. Anim. Endocrinol. 25:303-314.

17. SAYED-AHMED, A.; KULCSAR, M.; RUDAS, P.; BARTHA, T. 2004. Expression and localisation of leptin and leptin receptor in the mammary gland of the dry and lactating non-pregnant cow. Acta Vet. Hung. 52:97-111.

18. SILVA, L.F.; ETCHEBARNE, B.E.; NIELSEN, M.S.; LIESMAN, J.S.; KIUPEL, M.; VANDEHAAR, M.J. 2008. Intramammary infusion of leptin decreases proliferation of mammary epithelial cells in prepubertal heifers. J. Dairy Sci. 91:3034-3044.

19. SILVA, L.F.; VANDEHAAR, M.J.; WEBER NIELSEN, M.S.; SMITH, G.W. 2002. Evidence for a local effect of leptin in bovine mammary gland. J. Dairy Sci. 85:32773286.

20. THORN, S.R.; PURUP, S.; COHICK, W.S.; VESTERGAARD, M., SEJRSEN, K.; BOISCLAIR, Y.R. 2006. Leptin does not act directly on mammary epithelial cells in prepubertal dairy heifers. J. Dairy Sci. 89:14671477.
21. VERNON, R.G.; DENIS, R.G.; SORENSEN, A.; WILLIAMS, G. 2002. Leptin and the adaptations of lactation in rodents and ruminants. Horm. Metab. Res. 34:678-685.

22. WALL, E.; MCFADDEN, T. 2012. Regulation of Mammary Development as It Relates to Changes in Milk Production Efficiency. In: Narongsak Chaiyabutr (ed.). Milk Production - An Up-to-Date Overview of Animal Nutrition, Management and Health. Chapter 13.DOI: 10.5772/50777.

23. YAMAJI, D.; KAMIKAWA, A.; SOLIMAN, M.M.; ITO, T.; AHMED, M.M.; MAKONDO, K.; WATANABE, A.; SAITO, M.; KIMURA, K. 2007. Leptin inhibits hepatocyte growth factor-induced ductal morphogenesis of bovine mammary epithelial cells. Jap. J. Vet. Res. 54:183-189.

24. YONEKURA, S.; SAKAMOTO, K.; KOMATSU, T.; HAGINO, A.; KATOH, K.; OBARA, Y. 2006. Growth hormone and lactogenic hormones can reduce the leptin mRNA expression in bovine mammary epithelial cells. Dom. Anim. Endocrinol. 31:88-96.

Recibido: Septiembre 8 de 2014

Aceptado: Marzo 25 de 2015

\section{Cómo citar:}

Echeverry, D.; Ruiz-Cortés, Z.T. 2015. Expresión de receptores de leptina en glándula mamaria de bovinos lactantes y no lactantes. Rev. U.D.C.A Act. \& Div. Cient. 18(1): 171-179. 